\title{
A poética do ator e o encantamento na capoeira ${ }^{1}$
}

\author{
La poética del actor y el encantamiento en la capoeira
}

The poetics of the actor and the enchantment in capoeira

\author{
Dr. Mateus Schimith Batista²
}

\begin{abstract}
Resumo
Pela perspectiva da poética do ator, este estudo aborda a influência sonora na capoeira, refletindo sua concepção ritualística em aproximação com a prática cênica. Para isso, busca compreender a noção de estados corporais do ator em afinidade com a expressão transe capoeirano, cunhada pelo mestre de capoeira Decanio (2002), que a considera como um momento em que o jogador extrapola sua consciência como indivíduo, percebendo-se como integrante do ambiente no qual está inserido. Acredita-se, desse modo, que a musicalidade presente no jogo de capoeira seja o elemento fundamental para estabelecer o estado de corpo semelhante ao transe, o que permite investigar como essa relação pode ser determinante para entendimento dos estados de corpo na poética do ator.
\end{abstract}

Palavras-Chave: capoeira; poética do ator; transe; estados de corpo; musicalidade.

\section{Resumen}

Por la perspectiva de la poética del actor, este artículo aborda la influencia sonora en la capoeira, reflejando su concepción ritualista en aproximación con la práctica escénica. Para ello, busca comprender la noción de los estados corporales del actor en afinidad con la expresión trance capoeirano acuñada por Decanio (2002) que la considera como un momento en que el jugador extrapola su conciencia como individuo, percibiendo como integrante del entorno en el que está insertado. Para ello, se cree que la musicalidad presente en el juego de capoeira es el elemento fundamental para establecer el estado de cuerpo semejante al trance, lo que permite investigar cómo esa relación puede ser determinante para entendimiento de los estados de cuerpo en la poética del actor.

Palabras claves: capoeira; poética del actor; trance; estados de cuerpo; musicalidade.

\begin{abstract}
From the perspective of the actor 's poetics, this study deals with the influence of sound in capoeira, reflecting its ritualistic approach in relation to the scenic practice. In order to do this, it seeks to understand the notion of the body states of the actor in affinity with the expression transe capoeirano, coined by capoeira Mestre Decanio (2002), who considers it as a moment in which the player extrapolates his conscience as an individual, perceiving himself as part of the environment in which it is inserted. Thus, it is believed that the musicality present in the game of capoeira is the fundamental element to establish the state of body similar to the trance, which allows to investigate how this relation can be determinant for understanding the states of body in the poetic of the actor.
\end{abstract}

Keywords: capoeira; poetics of the actor; trance; body states; musicality.

1 Artigo apresentado no Simpósio Temático (Relações Étnico-Raciais na América Latina: debates interseccionais na diáspora) durante o II Seminário Latino-Americano de Estudos em Cultura - SEMLACult em Foz do Iguaçu/PR, Brasil, 2018.

2 Doutor em Artes Cênicas; Escola de Teatro - Universidade Federal da Bahia - UFBA; Salvador, Bahia, Brasil; mateus.sba@gmail.com 
Neste estudo, proponho pensar a influência da musicalidade para os estados corporais na capoeira, refletindo sua concepção ritualística em aproximação com a prática cênica. Esta aproximação - e suas respectivas tensões - entre as culturas da capoeira e do teatro nascem, na minha trajetória como ator-jogador, por meio de provocações que surgiram a partir da experiência continuada da capoeira e dos processos criativos em que questionei minhas compreensões acerca do corpo poético do ator. Trata-se de pensar como a musicalidade presente no jogo de capoeira, atribuída como elemento fundamental para um transe capoeirano, permite refletir sobre os estados de corpo na poética do ator.

A partir do entendimento de que o transe capoeirano, proposto por Decanio (2002), seria um momento em que o jogador amplia sua consciência como indivíduo, percebendo-se como integrante do ambiente da roda no qual está inserido, inicio do pressuposto de que a experiência de musicalidade ritualística, como a inserida no jogo de capoeira, potencializa sensações, percepções e/ou sentidos, de modo a criar um engajamento intenso e integral no corpo relacional ${ }^{i}$ do ator para o processo criativo e para o resultado em cena.

A escolha pela metodologia solidificou-se no interesse em articular questões teóricas que surgiram das minhas experiências como capoeirista, ao encontro das reflexões poéticas sobre o trabalho do ator (que, por sua vez, também nasceram, de forma geral, no campo das experiências). Tais proposições culminaram na elaboração da dissertação no Mestrado em Artes Cênicas pela Universidade Federal da Bahia (SCHIMITH, 2013).

Durante o Encontro Mundial de Artes Cênicas (ECUM) que ocorreu em Belo Horizonte - MG, em 2011, participei de uma oficina de imersão artística intitulada "Contato. Intenção. Impulso" com a coordenação de Thomas Richards (Workcenter of Jerzy Grotowski and Thomas Richards ${ }^{\mathrm{ii}}$ ). Nesta ocasião, foi desenvolvido um trabalho de investigação cênica, a partir de micro cenas trazidas pelos participantes e analisadas por Richards e sua equipe. Nesta oportunidade, também houve o treinamento diário de cantos de tradição que fazem parte do treinamento do grupo Workcenter.

Os cantos de tradição praticados pelo Workcenter são oriundos, em sua maioria, de práticas ritualísticas afro-caribenhas e, em alguns casos, do vudu haitiano (LIMA, 2013). Os trabalhos com os cantos são feitos de forma desassociada das manifestações culturais que os originam $^{\text {iii }}$. Como meio de investigação das possibilidades presentes na musicalidade desses 
cantos, o grupo pesquisa meios de fazer com que seus praticantes atores possam transformar e ampliar seus estados corporais em relação a si e na própria percepção do mundo ${ }^{\mathrm{iv}}$.

Tudo tem a ver com a sua qualidade [dos cantos], nossos cantos são especialmente escolhidos pela sua eficácia em colocar você mesmo frente a partes de você mesmo, têm a capacidade de chamar a sua alma ao seu ouvido. Por exemplo, você pode escutar um canto e sentir que você está realmente ouvindo, mas chega um momento em que algo dentro de você começa a ouvir, mas não é mais a orelha! Uma das peculiaridades desses cantos é chamar este algo de você para fora, para frente, da sua profundidade para sua superfície, e isso tem a ver com os diferentes aspectos de você mesmo, com a sua vida emocional, com a parte de você que prefere manter escondida na vida cotidiana ou que está relacionada com a força da sua vida, aquela força que leva você através das mil atividades que realiza durante todo o dia, e que te diz: 'eu quero isso!', uma espécie de fogo, uma força que gosta inclusive de ver sua marca na vida (Richards apud LIMA, 2013, p. 131).

Durante a prática introdutória com os cantos de tradição em que estive presente, percebi algumas especificações a respeito da experimentação com essa musicalidade. Inicialmente o treinamento começou com um rigoroso exercício vocal para que todos os participantes aprendessem a letra dos cantos e suas melodias (independentemente do entendimento do que era dito nas canções). Essa etapa do treinamento pressupunha também que todos os participantes fossem capazes de atingir registros vocais específicos do canto como é praticado em sua origem, mesmo que para alguns (como foi no meu caso) fosse uma tonalidade incômoda. $\mathrm{O}$ trabalho com os cantos estava cercado de uma investigação minuciosa por precisão.

Além disso, Richards solicitou que todos os participantes estivessem vestidos com roupas formais (calças compridas e camisa para os homens e saia longa e camisa para as mulheres). Tal pedido deixou demarcado entre os participantes de que aquela prática tratavase de um experimento ritualístico, no qual precisaríamos aprender a conviver com as suas

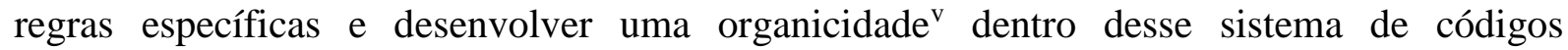
extracotidianos.

A partir do treinamento específico com a letra, a melodia e a tonalidade, o trabalho de experimentação com os cantos foi iniciado, partindo de um círculo, sem muita explicação ou justificativa. Entendia-se que um dos participantes representaria a voz principal e os demais participantes buscariam responder em coro, ocupando o espaço de trabalho e buscando relações corpóreas. O grande desafio, no entanto, não se tratava apenas de ser capaz de cantar em coro, mas de conseguir inserir todo o corpo nesse processo de vibração provocado pela voz cantada. 
Quando se começa a captar as qualidades vibratórias [dos cantos] isso encontra a radiação nos impulsos e nas ações. E então, de repente, aquele canto começa a cantar-nos. Aquele canto antigo me canta: não sei mais se descubro aquele canto ou se sou aquele canto. Atenção! Atenção! É o momento que requer vigilância, não se tornar propriedade do canto - sim, estar de pé (Grotowski apud LIMA, 2013).

Após uma semana de trabalho de estudo e experimentação com os cantos de tradição, dirigido por Thomas Richards, reconheço que foram poucos momentos, ou até mesmo pequenos instantes, em que o diretor percebeu uma corporeidade em mim disponível para um fluxo orgânico e preparado para construção de relações com os outros participantes. De modo que esse trabalho com os cantos demanda uma investigação constante e incessante em busca de despertar e aproveitar os momentos de uma integralidade somatossensorial oriunda da prática.

Percebi que os pequenos instantes em que Thomas Richards apontou em mim uma disponibilidade corporal para o canto de tradição aconteceram no momento em que os inúmeros códigos daquela prática foram minimamente assimilados e que eu pude encontrar uma liberdade improvisacional dentro desse círculo de regras da ritualística. Momentos em que eu realizava as ações sem que eu precisasse pensar nelas. Mesmo que, a princípio, pareça ser um caminho facilmente realizável, foram pequenas frações de tempo em que consegui atingir essa qualidade relacional que buscávamos.

A partir dessa experiência, comecei a refletir sobre os cantos de tradição utilizados pelo Workcenter na busca por um estado de corpo extracotidiano que pudesse apresentar ao ator outra percepção de si e do mundo. Nesse processo de investigação pessoal, notei que essa prática com os cantos apresentava, por meio da minha memória corporal, inúmeras relações com a prática da capoeira. Isso porque, entendo que a capoeira também apresenta inúmeros códigos que coloca seus participantes em uma situação extracotidiana, ao mesmo tempo que exige do jogador a capacidade de tornar essas regras orgânicas e de conseguir experimentar a improvisação e a liberdade dentro do contorno de regras.

O ritual da capoeira acontece em um espaço físico determinado, formado por um círculo (que varia de acordo com o ritmo do jogo) que é conhecido por roda de capoeira ${ }^{v i}$. É no centro dessa roda que acontece o jogo entre duas pessoas e as demais se posicionam em volta do círculo, de forma que todos possam ver o jogo acontecendo. Tal característica se aproxima do princípio da espacialidade cênica pensado para a realização do espetáculo teatral, uma vez que esse também pressupõe um espaço-tempo preparado para o olhar dos 
espectadores. De acordo com Barão (2008), durante o jogo de capoeira na roda, o tempo e o espaço habitual são modificados, colocando os jogadores em uma relação diferente com seu corpo e com o ambiente:

[...] o centro do círculo é onde se concentra a força cênica. $\mathrm{O}$ centro da roda de capoeira é onde o capoeirista se expressa. Não só o apontamento de um centro é importante, assim como, a passagem, o umbral que permite entrar e sair desse centro. No caso da roda, o pé-do-berimbau é o grande portal onde os performers entram e saem, se benzem, rezam, fazem suas louvações (BARÃO, 2008, p. 22).

As pessoas que ficam no círculo revezam-se entre os instrumentos percussivos, respondendo ao coro nos cantos e entrando na roda para jogar. O berimbau é o principal instrumento de musicalidade (acompanhados pelo atabaque, pandeiro, caxixe, agogô, recoreco e a palma das mãos), que direciona o ritmo das músicas a serem tocadas e cantadas, o que determina o compasso do jogo na roda. Tradicionalmente, um dos berimbaus, chamado de gunga, é tocado pelo jogador com maior hierarquia do grupo e considerado o regente da roda.

As músicas que são cantadas pelos participantes da roda assumem uma importante função no evento ritualístico. De acordo com Decanio (2002), os estímulos sonoros agem no jogador, que já se encontra em alerta pelo risco físico da luta, fazendo com que ele apresente sensações específicas do jogo de capoeira. Nesse sentido, Soares (2010, p. 52) concorda ao afirmar que "[...] a harmonia da música em sintonia com os capoeiristas favorece a epifania dos corpos em movimento, trazendo beleza e ludicidade aos movimentos precisos e atléticos de guerreiros e ao gingado com molejo do corpo solto de malandros".

Além da forte presença rítmica que a música oferece ao jogo de capoeira, observa-se ao contrário do que é proposto na investigação com os cantos de tradição, pelo Workcenter a contribuição das letras das músicas que se tornam presentes na prática, que além de dialogar com o que acontece durante o jogo, representa a manutenção de um conteúdo históricoliterário e um registro de uma tradição oral da prática e do praticante da capoeira.

São os instrumentos regidos pelo gunga que dita o ritmo do jogo dentro da roda, condicionando os jogadores a reagir aos estímulos sonoros na velocidade e nos tipos de movimentos utilizados na roda. Além disso, as canções utilizadas pelo regente da roda, durante o jogo da capoeira, frequentemente se relacionam com o contexto daquele, podendo servir tanto como estímulo, quanto provocação. Dessa forma, o evento ritualizado da 
capoeira, regido pelo fundamento da musicalidade, age diretamente no corpo de seus participantes, como um filtro que atravessa as experiências, fazendo com que eles vivenciem sensações diversas por longos períodos de repetições e que os induzem a modificar seus modos de agir.

Ao atribuir esses estados corporais a uma situação de transe, apesar de comum nos meios populares, envolve diversas particularidades que levam a questionamentos, desde superstições até psicopatologias. Não obstante, a socióloga Rizzi (1997, p. 80) percebe que, mesmo não havendo consenso para a definição de transe, é possível reconhecê-lo como um "[...] estado particular do indivíduo, durante o qual se evidencia modificações psicofísiológicas, num contexto ritual religioso. Tais estados são observados a partir de manifestações exteriores impressas no corpo da pessoa". Argumentarei, adiante, que tanto no caso dos cantos de tradição quanto no caso do transe capoeirano, essa noção se distancia dessa definição.

Vale observar que, na proposição de Decanio (2002), pode-se perceber uma mudança no estado corporal do indivíduo, que transita da sua própria individualidade para uma percepção dilatada dos estímulos somatossensoriais. Ou seja, para ele, esse transe capoeirano se concretiza na percepção do jogador de maior abertura para os estímulos externos, conservando seu estado de alerta e esquiva para lidar com a situação de perigo no jogo.

Esse estado acontece na capoeira, para Decanio (2002), também em reação à situação de perigo em que o jogador é colocado, mesmo que tenha ciência das regras, o que equivaleria, a certo modo, ao que Mestre Bimba ${ }^{\text {vii }}$ considera como instinto de autopreservação, um estímulo que leva o jogador a esquivar-se e a atacar, para além de seu controle voluntário. $\mathrm{O}$ pesquisador explica que

[...] durante o Transe Capoeirano, o capoeirista modifica o seu estado emocional e passa a encarar como prazerosa uma situação de risco imaginário sob a proteção do ritual e vigilância e responsabilidade do Mestre, de modo a facilitar o aprendizado e o registro de soluções adequadas às pretensas situações de perigo (DECANIO, 2002, p. 20).

O autor ainda afirma ser o estado de transe um resultado de uma corrente de estímulos, inicialmente e principalmente sonoros, oferecida pelos instrumentos da capoeira, que levam o jogador a um determinado ritmo ${ }^{\text {viii }}$. O pesquisador atribui tal efeito à semelhança da musicalidade existente na religião do Candomble $e^{i x}$, em que, a partir de cantos acompanhados 
por atabaques, seus participantes chegam ao estado de perda do controle do pensamento racional, o transe.

De acordo com Luhning (1990), a música, a dança e a letra estão intrinsecamente ligadas ao estado de transe no candomblé, ainda que, para muitos, seja apenas um fator estimulante. Da mesma forma, entendo que o efeito da musicalidade provocada pelos instrumentos e pelo coro da capoeira nos corpos dos jogadores, são indispensáveis para estabelecer um estado corporal específico para a sua prática.

Nos estudos teatrais, o termo transe também está presente, sobretudo nos estudos dedicados ao desenvolvimento da perspectiva da organicidade no trabalho do ator. Sobre os relatos de Artaud (1993), o pesquisador Alain Virmaux (1990), discute a proximidade da descrição da transgressão do ator em cena por meio do transe. Artaud, ao afirmar que o ator “[...] entra em transe através de métodos calculados” (ARTAUD, 1993, p. 12), opõe-se à ideia de que o transe se trata da perda do controle dos atos pelo sujeito. Luiz Otávio Burnier (2001, p. 205) comunga com essa ideia ao afirmar que, no teatro, “[...] o ator não recebe uma entidade, mas suas próprias energias ganham curso livre. É como se ele entrasse numa espécie de transe com suas próprias energias". Tal pensamento também é apresentado como uma oposição aquele defendido pela antropóloga Rizzi (1997). Nesses casos, parece claro o objetivo de colocar o ator em estados que o leve para além do controle racional, incentivandoo à escuta do próprio corpo, intuitivo e instintivo.

Em Grotowski (1992), a concepção de transe atribuída ao trabalho do ator passou por modificações com o tempo: primeiramente, o encenador havia usado o termo para explicar a necessidade de seus atores desenvolverem experiências corpóreas que fossem além dos moldes realistas, por meio de terapias corporais como ioga. Ao entender que essa via não era eficaz, abandonou a utilização do termo para essa conotação. Em 1982, o transe passou a ser associado por ele como organicidade, como um tipo de atenção e consciência desenvolvida pelo ator. Nesse período, Grotowski já havia tido experiências com inúmeros rituais tradicionais, no Haiti, na Índia e no México, por exemplo e incorporados às práticas investigativas de seu grupo, Workcenter (LIMA, 2008).

Barba (1995), a partir de suas experiências com Grotowski, também descreve o transe, mas de duas formas diferentes: a primeira, como concentração e mobilização de energias interiores que os ajudassem em suas intenções; e, na segunda, o termo foi utilizado em 
associação à ideia de autopenetração como "ataque aos pontos nevrálgicos da psique mediante associações de ideias" e "uma manutenção de vitalidade" (LIMA, 2008, p. 97).

Biagini, segundo Lima (2013), atribui ao trabalho investigativo dos cantos tradicionais utilizados pelo Workcenter, a possibilidade de transformação do atuante na própria percepção do mundo e de si mesmo no mundo, interferindo na qualidade de presença. Desta forma, torna-se importante destacar que Grotowski não pressupunha uma alteração do estado de consciência do ator, mediante aos cantos, mas um alargamento de sua percepção (LIMA, 2013, p.225).

Ou seja, tanto o caso do transe capoeirano, quanto a perspectiva do transe proposta por Grotowski, passam pela manutenção das capacidades de tomadas de decisão do atuante/jogador, somadas a uma ampliação dos sentidos somatosensoriais que os permitem perceber o espaço-tempo e se perceber organicamente nele de uma forma singular e subjetiva.

Nesse sentido, tratando-se das experiências dessas memórias corporais como ator/capoeirista, é possível notar uma aproximação entre os pensamentos de Decanio (2002) e os caminhos artísticos mais atuais do Workcenter, impulsionados por Grotowski (1992) em sua última fase, lidando com estados de corpo a partir de estímulos sonoros, presente em cantos - no caso de Decanio (2002), os cantos da capoeira e, no de Grotowski, os cantos principalmente afro-caribenhos.

Pode-se observar que o Workcenter desenvolve meios de se chegar a estados de corpos orgânicos partindo de uma neutralidade do corpo, por meio dos cantos de tradição, despertando na prática de cantar o sentido de coletividade de todos os envolvidos (entre cantor principal, coro e espectador). Na prática de capoeira, apontada por Decanio (2002), esse sentido de coletividade também se torna importante para se estabelecer esses estados.

Em todos esses casos, a noção de transe, associada ao fundamento da musicalidade presente nas culturas ritualísticas, propõe levar o indivíduo ao aumento das suas percepções corporais, de modo que deixe de entender-se apenas como indivíduo limitado por sua substância e passe a compreender-se como um corpo relacional, integrado e agente no ambiente em que está inserido. Essa busca por uma corporeidade capaz de afetar e se deixar afetar pelo ambiente se demonstra como o ponto de convergência da busca pelo transe, tanto na capoeira quanto no teatro. 


\section{Referências}

ARTAUD, A. O Teatro e seu Duplo. Tradução: Teixeira Coelho. São Paulo: Martins Fontes, 1993.

BARÃO, A. C. A Performance Ritual da Roda de Capoeira. 181f. Dissertação (Mestrado em Artes) - Instituto de Artes, Universidade Estadual de Campinas, Campinas, 1999.

BARBA, E.; SAVARESE, N. A arte secreta do ator. Tradução: Luiz Otávio Burnier. São Paulo: Hucitec, 1995.

BURNIER, L. O. A Arte de Ator: da técnica à representação. Campinas: Unicamp, 2001.

CHAUI, M. S. Espinosa: uma filosofia da liberdade. São Paulo: Editora Moderna, 2001

DECANIO, A. A. Transe Capoeirano. Salvador: 2002. (Coleção Salomão, n. 05).

GROTOWSKI, J. Em Busca de um Teatro Pobre. Tradução: Aldomar Conrado. 4. ed. Rio de Janeiro: Civilização Brasileira, 1992.

LIMA, T. M. "Cantem, pode acontecer alguma coisa": em torno dos cantos e do cantar nas investigações do Workcenter of Jerzy Grotowski and Thomas Richards. Revista Brasileira Estudo da presença, Porto Alegre, v. 3, n. 1, p. 220-240, jan./abr. 2013.

LIMA, T. M. Les Mots Pratiques: relação entre terminologia e prática no percurso artístico de Jerzy Grotowski entre os anos 1959 e 1974. 2008. 366 f. Tese (Doutorado em Artes Cênicas) - Universidade Federal do Rio de Janeiro, Rio de Janeiro, 2008.

LUHNING, A. Música: coração do candomblé. Revista USP, São Paulo: USP. p. 115-124. 1990.

PASTINHA, V. P. Capoeira Angola, por mestre Pastinha. 3. ed. Salvador: Fundação de Cultura do Estado da Bahia, 1988.

RIZZI, N. D. Visões do Transe Religioso, Revista Plural, São Paulo: USP, p. 78-106, 1997.

SCHIMITH, M. Estados de Corpo: vias de aproximação entre capoeira e teatro na poética de um ator. 2013. 112 f. Dissertação (Mestrado em Artes Cênicas) - Programa de PósGraduação em Artes Cênicas, Universidade Federal da Bahia, Salvador, 2013.

SOARES, M. C. Roda de Capoeira: rito espetacular. 2010. 93 f. Dissertação (Mestrado em Artes Cênicas) - Universidade Federal de Minas Gerais, Belo Horizonte, 2010.

VIRMAUX A. Artaud e o Teatro. Trad. Carlos Eugênio Marcondes de Moura. São Paulo: Perspectiva, 1978.

i Ao utilizar essa expressão, considero o ponto de vista do filósofo Espinosa, ao negar o homem como uma substância ou composto substancial. O corpo espinosano, como ressalta Chauí (2001, p. 55), é considerado como "uma individualidade dinâmica e intercorpórea" e "[...] por essência, o corpo é relacional: é constituído por relações internas entre seus órgãos, por relações externas com outros corpos e por afecções, isto é, pela 
capacidade de afetar outros corpos e ser por eles afetado sem se destruir, regenerando-se com eles e os regenerando. O corpo, sistema complexo de movimentos internos e externos, pressupõe e põe a intercorporeidade como originária" (CHAUÍ, 2001, p. 54).

ii Grupo de Teatro criado por Grotowski em 1986, em Pontedera - Itália, hoje é coordenada por Thomas Richards.

iii Segundo Lima (2013), na prática de Grotowski reconhece-se o risco que estava correndo de utilizar elementos de determinadas manifestações culturais devinculando-os de suas crenças, mas permanecia nesse pesquisa com a postura de um investigador que busca verificar a potência destes elementos aplicados à pratica do ator na descoberta de si.

iv Para mais informações a respeito das práticas do Workcenter com os cantos tradicionais, indico a leitura do artigo "Cantem, pode acontecer alguma coisa: em torno dos cantos e do cantar nas investigações do Workcenter of Jerzy Grotowski and Thomas Richards" (LIMA, 2013).

v A organicidade é uma noção complexa que diz respeito a um nível de organização interna do corpo do ator ao executar determinada ação (mesmo que esta seja manter-se imóvel) (BURNIER, 2001). Logo, “[...] para se obter uma organicidade em uma ação física, ou em uma sequência de ações físicas, há de se desenvolver um conjunto complexo de ligações e interligações internas à ação ou à sequência das ações” (BURNIER, 2001, p. 53).

vi A roda de capoeira foi reconhecida, em 2014, como Patrimônio Cultural Imaterial da Humanidade pela UNESCO, por meio da publicação Convention pour la sauvegarde du Patrimoine Culturel Immateriel - Le Cercle de capoeira. Paris: UNESCO, 2014.

vii Manoel dos Reis Machado (1900-1974), o Mestre Bimba, é o criador do método da capoeira Regional.

viii De acordo com Decanio (2002), o ritmo/melodia é capaz de ensinar o jogador de capoeira a lidar com o jogo, estando acima da compreensão histórica ou técnica do jogo.

ix O Candomblé é uma religião de origem africana, trazida ao Brasil (estabelecendo-se também em outros países da América Latina) ainda no período escravocrata, que se desenvolveu de forma oculta, assim como a capoeira, em um período em que não era aceita a prática de outras religiões além do cristianismo. 